\title{
EVALUATE THE ENVIRONMENTAL CRISES AND DISASTERS AND ITS EFFECTS ON AVIATION SAFETY.
}

Mona M. K.R.M. Fouad ${ }^{1}$, Aida M.ALLam² ${ }^{2}$ Khalid Hanafy : ${ }^{3}$ Galal D.Eldeen M,Roshdy ${ }^{4}$

${ }^{1}$ Researcher Doctorate of Philosophy in Environmental Sciences (2015)

${ }^{2}$ Dept Natural Resources Evaluation Environmental Studies and Research Institute EL Sadat City University.

${ }^{3}$ minister of supply and foreign trade - dean of college of international transport-Arab Academy for maritime transport.

${ }^{4}$ Head of the Operations Sector - Cairo International Airport Co.

\section{INTRODUCTION}

Aviation is one of the world's great connectors of people, trade and tourism. It enhances the prosperity of communities serves, provides jobs, skills and opportunities. It is the real world wide web- a network of airlines, airports and air traffic control organisations that link the major cities and small communities of the world 24 hours a day with very advanced aircraft. (Giovanni Bisignani Declared; 2006).

Aviation is remarkable for giant technological leaps it has made over the last century. This progress would not have been possible without parallel achievements in the control and reduction of aviation's safety hazards. Aviation is interdependent. The consequences of a major air disaster can affect many of the stakeholders. Mutual concern over damage to the industry's reputation, goodwill and public confidence trends to promote collective action over the parochial pursuit of special interest (ICAO, Doc 9859.SMS; 2006).

A natural disaster is a major adverse event resulting from natural processes of the Earth; examples include floods, volcanic eruptions, earthquakes, tsunamis, and other geologic processes. A natural disaster can cause loss of life or property damage,(http://www.ncdc.noaa.gov/billions), and typically leaves some economic damage in its wake, the severity of which depends on the affected population's resilience, or ability to recover .(G. Bankoff, G. Frerks, D. Hilhorst; 2003).

In the new millennium, most major crisis and emergencies are no longer national and local concerns; they are global concerns and require global attention. For example, problems causing atmospheric and environmental crisis demand multinational and global cooperation. Crisis have always inflicted heavy costs on human lives, organizations, and governments. While some crisis are natural and usually unpredictable, others are human-engineered and can be avoided or prevented through elimination of their sources. (Birkland; 1997).

For any organization, a disaster is an incident or a series of incidents in a short period of time that:

- Cause major injury and/or loss of life;

- Cause major destruction of property;

- Halt or curtails operations for a significant period of time; 
- $\quad$ Prevent employees from pursuing their normal duties;

- Cause a substantial reduction in purchases of products or services;

- $\quad$ Bring the organization under scrutiny by media or government.

RETRIEVED FROM ( EGYPTAIR,EDITION.3/MAY;2012).

الملخص

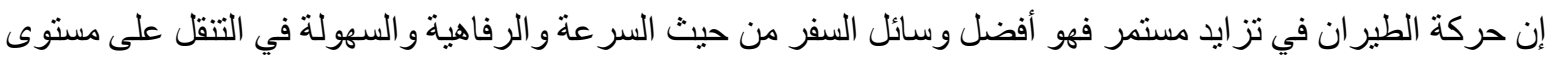

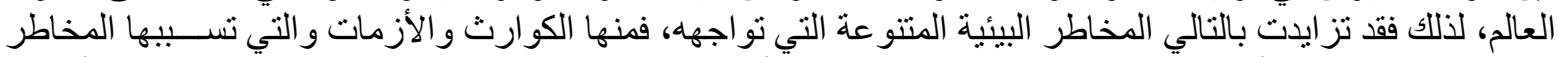

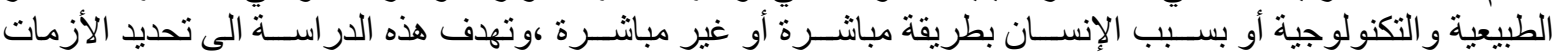

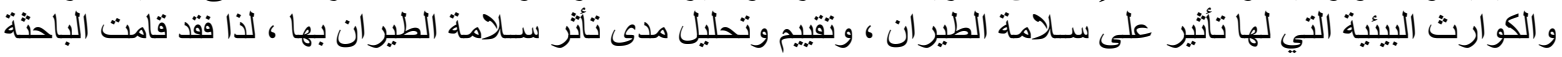

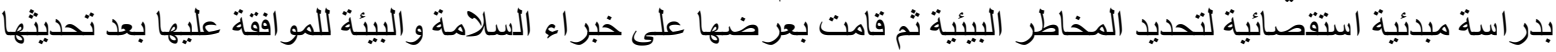

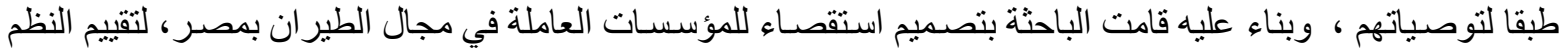

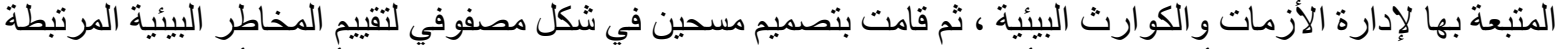

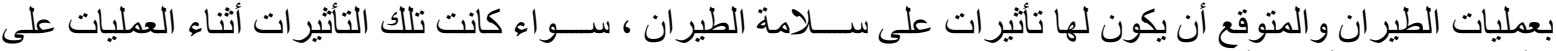

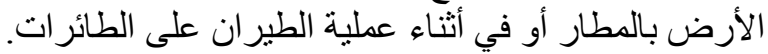

نتائج الاراسة : وبتطبيق الاستقصاء والمسحين وتحليل النتائج توصلت الباحثة لعدد من النتائج وهي :

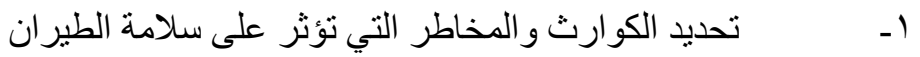

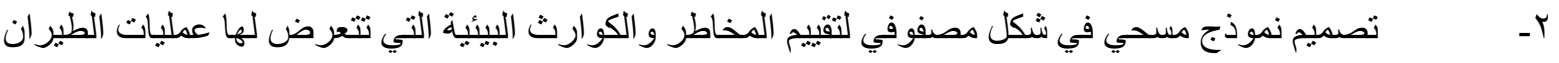
بـ- و العمليات الأرضية بالمطار ات.

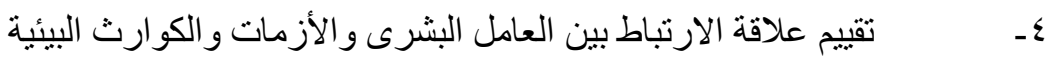
هـ ـ وكذلك قامت باقتر اح مجموعة من التوصيات الموجهة للمؤسسات العاملة بالطيران وكذا للبحوث المستقبلية .

\section{THE THESIS OBJECTIVES}

- Illustrating the impact of air transport on environment.

- Identifying environmental risks confronted the aviation safety and its causes.

- Clarifying the environmental disasters and crisis associated with climate changes.

- Measuring and analyzing risks to avoid crisis and reduce the impact of the environmental disasters.

- Assessing the effects of environmental disasters and crisis on aviation safety.

- Evaluating the environmental disaster and crisis risk on aviation activities.

- Recommending model plan to apply risk assessment for environmental crisis and disasters on aviation safety.

\section{REVIEW OF LITERATURE}

The desk research depended on The past studies and researches, conferences, formal websites and Literature on the following topics:

- Aviation and Environment .

- Environmental Disasters.

- The Crisis. 
- Aviation safety.

- Human factor in aviation.

\section{MATERIALS \&METHODOLOGY}

\section{A-IDENTIFY THE PROBLEM:}

This study was focused on the following points:

- The importance of aviation industry.

- $\quad$ The invest on environment-friendly technology.

- The environmental crises and disasters hazards on aviation.

- The role of human factor for reducing environmental risks in aviation safety.

- Environmental crisis and disasters risks which facing the aviation safety.

\section{B- THE IMPORTANT OF THE RESEARCH}

- Environmental disasters: natural, technological, social and man-made risks. The risk of Environmental disasters and crisis and its effects on aviation.

- The development of an integrated approach to identify and to measure the environmental hazards for the purpose of preparedness and reduce the negative consequences on aviation safety.

- Developing an Environmental Risk matrix, which, can be used as a guide for predicting Environmental hazards at any airport or on board an aircraft during flight phases.

- Environmental hazards and its effect on Aviation safety.

- The urgency of measuring and analyzing to avoid crisis and reduce the impact of the environmental disasters.

\section{C- METHODOLOGY}

The researcher applied two tools to identify the Disaster risks:

The first tool was "questionnaire" technique for evaluating the Environmental Crises \& Disasters management in aviation organizations in Egypt. The questionnaire contains organized question for measuring the following areas:

Section 1 - Organization and Management System,

Section 2 - Planning and structure,

Section 3 - Communications.

The second tool was risk assessment survey: the researcher applied two surveys based on real variables for two situations:

- "Environmental disasters and risks at airports", applied on Environment and safety officers at airports and Air traffic control, It had been applied on Egyptian airports safety officers and environmental staff. Also, air traffic controller (Safety and environment officers). 
- "Environmental disasters and risks during Flight operations phases", applied on pilots (flying crew).

\section{PROCEDURE FOR PERFORMING A RISK ASSESSMENT}

During the survey design phase, The researcher put in consecration the four risk assessment general steps according to (ISO 31010; 2009) :

- Risk Identification: The risk identification process includes identifying the causes and source of the risk (hazard in the context of physical harm), events, situations or circumstances, which could have a material impact upon objectives and the nature of that impact.

- Risk analysis: Risk analysis consists of determining the consequences and their probabilities for identified risk events, taking into account the presence (or not) and the effectiveness of any existing controls. The consequences and their probabilities are then combined to determine a level of risk.

- Risk evaluation: Risk evaluation involves comparing estimated levels of risk with risk criteria defined when the context was established, in order to determine the significance of the level and type of risk.

- Documentation: The risk assessment process should be documented together with the results of the assessment. Risks should be expressed in understandable terms, and the units in which the level of risk is expressed should be clear, (ISO 310102009).

- Risk characterization - describe nature of adverse effects, their likelihood, and the strength of the evidence behind these characterizations (often done by using probability and statistics), (Dolbeer, R. A., S. E. Wright, and E. C. Cleary; 2000).

\section{RISK IDENTIFICATION METHODS CAN INCLUDE:}

Evidence based methods, examples of which are check-lists and reviews of historical data. Systematic team approaches where a team of experts follows a systematic process

Identify risks by means of a structured set of prompts or questions.

Irrespective of the actual techniques employed, it is important that due recognition is given to human and organizational factors when identifying risk. Hence, deviations of human and organizational factors from the expected should be included in the risk identification process as well as "hardware" or "software" events, according to: (ISO 31010-2009).

A structured approach to the identification of hazards may include the use of group brainstorming sessions in which subject-matter experts conduct detailed analysis scenarios. Hazard identification sessions require a range of experienced operational and technical personnel and are managed by a facilitator. The same group may also be used to assess corresponding safety risks, (ICAO Doc 9859; 2013).

Qualitative assessment defines severity, probability and level of risk by significance level, by combine the severity and probability and evaluates the resultant level of risk against qualitative criteria. 
Care should be taken to ensure that they are not attributed a level of accuracy and precision inconsistent with the accuracy of the data and methods employed.

Risk analysis consists of determining the severity and their probabilities for identified risk events, taking into account the presence (or not) and the effectiveness of any existing controls. The severity and their probabilities are combined to determine a level of risk. (ISO 31010 - 2009).

A structured approach to the identification of hazards may include the use of group brainstorming sessions in which subject-matter experts conduct detailed analysis scenarios. Hazard identification sessions require a range of experienced operational and technical personnel and are managed by a facilitator. The same group may also be used to assess corresponding safety risks, (ICAO Doc 9859; 2013).

\section{RESULTS AND DISCUSSION}

\section{A-THE RESULT OF THE QUESTIONNAIRE "EVALUATING THE ENVIRONMENTAL} CRISES \& DISASTERS MANAGEMENT IN AVIATION ORGANIZATIONS" IN EGYPT, DEALETED WITH THAT:

- The aviation organizations has Environmental Crises Management System.

- The aviation organizations has procedure regarding the establishment of minimum headcount requirements to meet operational environmental risk. In addition, the organization has training unit has appropriate training facilities, devices, equipment, and course material.

- The aviation organization has procedure regarding the establishment of minimum headcount requirements to meet operational environmental risk. In addition, the organization has training unit has appropriate training facilities, devices, equipment, and course material (whether owned or subcontracted) to conduct Safety Management training programs for all staff.

- Training Unit has not procedures to check if a new course design initiative related to environmental crisis training is in line with the latest standards approved by the Civil Aviation Authority or the International Standard Regulator. Training Unit has not appropriate training facilities, devices, equipment, and course material (whether owned or subcontracted) to conduct Environmental Crisis Emergency training programs for all staff.

- The aviation organization has a positive communication for Environment crisis management

\section{B- SURVEY RESULTS: ENVIRONMENTAL DISASTER AND RISKS AT AIRPORT}

The researcher applied the Environmental disasters and Risk Assessment Matrix. The respondents were asked to evaluate the probability (frequency) and severity about many environmental risks and its effects on taxi way, apron, workshops, airport stores/depot and airport buildings. These risks are divided into five groups as presented in Table 4. Indeed, probability is scaled from 1 [extremely improbable] to 5 [frequent] and similarly severity is scaled from 1 [negligible] to 5 [catastrophic]. Results of the evaluation of probability and severity for the Environmental risks are presented in Table 4. In addition, the colors are also presented in the cells of the table based on the fourth fundamental risk assessment of (ICAO Doc 9859, 2013), since green means low risk, yellow means medium risk, and red means high risk. For the first group, environmental disasters, results show that there is on average medium risk of volcanoes and volcanic ash for taxi way, apron, airport stores/depot and airport buildings, and low 
risk for workshops. In addition, results show medium risk of Earthquakes and low risk of Tsunami for all airport locations, also show low risk of Flooding and medium risk of Desertification for taxi way and apron; and on the other hand, show medium risk of Flooding and low risk of Desertification for workshops, airport stores/depot and airport buildings. For the second group includes man-made disasters, results show that there is on average medium risk of all man-made disasters for all airport locations, except fire has high risk for workshops and de-icing has high risk for all airport locations. For the third group includes weather disasters, results show that there is on average medium risk for all disasters except Frozen precipitation and icing have low risk for all airport locations. For the last two groups, topography and wild life animals, there are on average low risk for topography and medium risk Wild life for all airport locations. Since the human factor is very important and related to the skills and experiences of employees at airport, therefore we computed the correlation between the human errors and all other risks at airport other man-made risks and with most of weather disasters, and is weak to moderate with most of topography and wild life disasters.

\section{C- SURVEY RESULTS: ENVIRONMENTAL DISASTER AND RISKS DURING FLIGHT OPERATION PHASES}

The respondents are asked to evaluate the probability (frequency) and severity about many environmental risks and its effects on flight operations, which include taxi out, take off, climb, cruise, descent, approach, and landing and on ground. These risks are divided into five groups similar to the survey of environmental risks at airport. Probability is scaled from 1 [extremely improbable] to 5 [frequent] and similarly severity is scaled from 1 [negligible] to 5 [catastrophic]. For the first group, environmental disasters, results show that there is on average medium risk of all the environmental disasters for most of the flight operation phases, except Cosmic rays and solar wind have low risk. For the second group, includes man-made disasters, results show that there is on average medium risk of all man-made disasters for all the flight operation phases, except Nuclear Emissions has low risk for taxi out and cruise, airport Infrastructure and foreign objects damages (FOD) have low risk for takeoff , climb, cruise, descent, and approach, and Laser beams and Chemical liquids spill have low risk for all the flight operation phases. There is high risk for few cases; such aircraft weight and balance risk for landing, and Collisions risk for cruise and approach. For the third group includes weather disasters, results show that there is on average medium risk for all disasters for all the flight operation phases except few cases of low and high risk. For the last two groups, topography and wild life animals, there are on average medium risks for all the flight operation phases except few cases of low risk.

\section{CONCLUSIONS AND RECOMMENDATIONS}

\section{THE CONCLUSIONS:}

The results of the questionnaire showed that there is a week point in the system of safety training which is related to the crisis and disaster training program. In addition, the aviation industries have safety training unite, but not updated according to new standards, and the training unite does not have appropriate facilities to apply efficient training.

Human-made hazards can result in the form of a human-made disaster. 


\section{THE RECOMMENDATIONS}

All aviation institution are requested to be involved in the following:

- Taking a proactive approach to environmental crisis management by developing a crisis management plan depending on"risk assessment information system".

- The necessity to enhance the developing policies and applying procedures to reduce risk of environmental hazards in aviation field, without harming aviation safety.

- The necessity of coordinating between those in charge of airports and institutions of aviation to protect health of workers, travelers and inhabitants around airports from the environmental crisis and disasters.

- Selecting The Crisis management team based on competences is a crucial for successful crisis management

- Raising the awareness of the workers about the environmental variables related Hazards, crisis, disasters.

- Continuous Training and simulation exercises for all staff are invaluable in preparation for crisis management.

- Open more communication channels within stakeholder, which would eventually increase effectiveness of crisis management.

- Using the new technology and automation systems for monitoring and controlling environmental risk are effective to insure the aviation safety.

- Traditional means of communication have become ineffective in the present. However, using social media, formal websites, electronic surveys are fashionable way to communicate with interested people and stakeholders.

\section{RECOMMENDATIONS FOR RESEARCHERS:}

Future research might utilize more disaster and crisis cases, search for the impact of applying different communication techniques and best practices within a system, study the relationships among members of crisis management networks to reach the stakeholder efficiently.

\section{REFERENCE}

- Brikland, Thomas A.; 1997,"After Disaster: Agenda Setting, Public Policy, and Focusing Events", Georgetown University Press, 1997.

- Dolbeer, R. A., S. E. Wright, and E. C. Cleary; 2000, "Ranking the hazard level of wildlife species to aviation", Wildlife Society Bulletin 28:372-378.

- Egyptair;May 2012,"Emergency response plan", edition (3).

- G. Bankoff, G. Frerks, D. Hilhorst; 2003, (eds) " Mapping Vulnerability: Disasters, Development and People". ISBN 1-85383-964-7

- Giovanni Bisignani Declared; 2006, "IATA global aviation \& Environment summit" on 2006 in Geneva. Accessed 21-04-2008, on (http://www.enviro.aero/WhatWeAreDoing.aspx).

- ICAO; 2006, "Safety Management Manual (SMM)", ICAO Doc 9859, 
$1^{\text {st }}$ edition, 2013.

- ICAO; 2013, "Safety Management Manual (SMM)", ICAO Doc 9859, third edition, 2013.

- ISO 31010; 2009, "Risk management- Risk assessment techniques".

- (http://www.ncdc.noaa.gov/billions) ; NOAA's National Centers for Environmental Information (NCEI);2014,"U.S. Billion-dollar Weather and Climate Disasters". 